Brazilian Journal

of Chemical

ISSN 0104-6632

Printed in Brazil

Engineering

\title{
EFFECT OF FLUIDIZED-BED PROCESS VARIABLES ON CONTROLLED-RELEASE OF NITROGEN AND COATING
}

\author{
Babar Azeem ${ }^{1}$, KuZilati KuShaari ${ }^{*}$, Zakaria Man ${ }^{1}$ and Thanh H. Trinh ${ }^{1}$ \\ ${ }^{1}$ Universiti Teknologi PETRONAS, 32610 Bandar Seri Iskandar, Perak Darul \\ Ridzuan, Malaysia
}

(Submitted: July 9, 2016; Revised: November 30, 2016; Accepted: January 29, 2017)

\begin{abstract}
Pristine urea is lost due to ammonia volatilization and leaching causing toxic emissions and eutrophication. Controlled-release urea is employed as an abatement strategy. Most of the synthetic polymers used to produce controlled-release urea are non-biodegradable and expensive. To offset this problem, modifiedstarch biopolymer is used as coating material to produce controlled-release urea in fluidized bed. The effect of different process variables is studied on release characteristics and coating uniformity of coated urea. The product has better release characteristics. The statistical analysis reveals that fluidizing gas temperature and coating time are the most influential variables. The nutrient release time increases with increase in coating time and decreases with increase in fluidizing gas temperature beyond a certain limit. Coating uniformity, significant thickness and film integrity are required for promising release characteristics. Urea release followed non-Fickian diffusion and Case-II transport. This study can help produce green fertilizer at bigger scale.
\end{abstract}

Keywords: Coating uniformity, Controlled-release urea, Release characteristics, Fluidized-bed coating, Green fertilizer.

\section{INTRODUCTION}

Pristine urea is lost from $30-70 \%$ due to ammonia volatilization, leaching and surface runoff ( $\mathrm{Naz}$ and Sulaiman, 2016; Niu and Li, 2012) causing low nutrient use efficiency (NUE) and environmental pollution due to nitrogenous emissions and water eutrophication (Lubkowski et al., 2015). Controlled-release coated urea $(\mathrm{CRCU})$ is employed to offset this discrepancy. The CRCU, produced by physical intromission of urea granules by some organic/inorganic material, makes nitrogen release in a controlled manner preferably in synchrony to the metabolic needs of the plants. It can augment NUE; eradicate nutrient loss, abolish environmental pollution, and reduce the cost due to a single application to the crops (Al-Zahrani, 2000; Ko et al., 1996).

Initially, sulfur has been used for the production of CRCU (Blouin et al., 1971, Ayub et al., 2001). However, high cost, inconsistent results and additional requirements of sealants, plasticizers, binders and protective agents led to process complexity and thus, sulfur coatings have almost been abolished (Jin et al., 2013). Organic polymers such as polyolefins , polyethylene, polyurethane, polystyrene, acrylic acidco-acrylamide, and polysulfone (Cong et al., 2010) offer good controlled-release characteristics, batch to batch uniformity and water retention properties when

* Corresponding Author. CSIMAL Block J, Universiti Teknologi PETRONAS, 32610 Bandar Seri Iskandar, Perak Darul Ridzuan, Malaysia .Email: kuzilati_kushaari@utp.edu.my, Ph.: +6019 4107181, Fax: +60 5-365 4088. Email: engrbabara@gmail.com; kuzilati_kushaari@utp.edu.my; zakaman@petronas.com.my; onalone2000@gmail.com 
used as coating materials (Chiellini and Solaro, 1996). However, most of the polymers used are expensive, non-biodegradable, and non-environmentally-friendly (Hemati et al., 2003). Approximately $50 \mathrm{~kg} / \mathrm{ha}$ per year of the useless material is left in the soil due to non-biodegradability of polymers which poses another kind of soil pollution (Al-Zahrani, 2000). To offset these issues, green, cost effective, renewable and biodegradable materials as coating agents are under consideration (Mekonnen et al., 2013). Several studies have been reported for the use of such materials including starch (Chen et al., 2008), Lignin and cellulose derivatives (Fernandez-Perez et al., 2008), and chitosan (Melaj and Daraio, 2013) as coating agents to produce controlled-release fertilizers (CRFs).

Starch is a cheap, biodegradable, renewable and environmentally friendly naturally occurring polysaccharide available in abundance (Niu and $\mathrm{Li}$, 2012). However, due to its augmented hygroscopic nature and poor dimensional stability, starch-alone fails to secure its candidature as a promising coating material (Jin et al., 2013). Modified starch, on the other hand, has been reported to exhibit good controlled-release characteristics. Starch blends with polyvinyl alcohol (PVOH) result in good release properties and eco-friendliness. In addition, $\mathrm{PVOH}$ significantly enhances the mechanical strength of the hydrogel (Fernandez-Perez et al., 2008). Starch-based controlled-release formulations and their applications have been discussed elsewhere (Riyajan 2012, Lum et al., 2016).

Coating methods to produce CRFs include immersion technique (Lubkowski et al., 2015), rotary pan/drum coating (Dhaese, 2014), and film coating in fluidized/spouted beds (da Rosa and dos Santos Rocha, 2013). Coating in the fluidized-bed is considered more appropriate due to superior heat and mass transfer characteristics, good mixing, coating uniformity, and reduced processing time (Salman et al., 2007). It is important to study the effect of fluidized-bed process conditions that affect the quality of CRFs. The choice of appropriate conditions is imperative as the inapt conditions may result in poor quality and economic loss (Pissinati and Oliveira, 2003). The effect of atomizing pressure, spray rate, and fluidizing air temperature on coating efficiency, particle growth (Donida and Rocha, 2002; da Rosa and dos Santos Rocha, 2010), film structure (Lan et al., 2011), and coating quality (Weiss and Meisen, 1983) has been studied using urea as a substrate. Blouin et al. (1971) and Ayub et al. (2001) investigated the effect of atomizing air pressure on controlled-release of urea. Salman et al.
(1988) studied the controlled-release characteristics of urea as a function of spray flow rate. Tsai et al. (1986) and Ayub et al. (2001) also studied the effect of fluidizing air temperature on controlled-release of urea. Naz et al. (2015) examined the dependency of coating thickness and controlled-release of urea on spray solution temperature in a fluidized-bed coater.

Preferential coating due to unequal chances of granules to come across the spray zone gives rise to coating heterogeneity (Abe et al., 1998). The coating heterogeneity may lead to poor controlled-release characteristics. Therefore, it is important to investigate the effect of process conditions on urea coating uniformity (Dhaese, 2014). Coating uniformity has been studied using glass beads (Abe et al. 1998), pharmaceutical tablets (Dhaese, 2014; Lustrik et al., 2012), and sugar flakes (Jozwiakowski et al., 1990) as substrates. Coating mass variance (Tobiska and Kleinebudde, 2003), coating mass to pallet surface area (Lustrik, 2012), and variance of coating thickness have been employed as a measure of coating uniformity.

The literature suggests that promising controlledrelease characteristics are achieved at the cost of non-biodegradability of the coating material, process complexity, and the overall cost. Moreover, the effect of fluidized-bed process variables is important to study for optimum coating uniformity and release characteristics. The effect of process parameters affecting coating uniformity and release characteristics of CRCU produced in a rotary fluidized-bed coater (RFBC) using PVOH-modified starch biopolymer as coating material has not yet been systematically investigated. In this study, the effect of fluidized-bed process variables on coating uniformity and release characteristics of starch-based CRCU produced in RFBC has been investigated.

\section{MATERIALS \& METHODS}

\section{Materials \& pre-treatment}

Granular urea from PETRONAS Fertilizer (Kedah) Sdn Bhd was subjected to sieve analysis and the granules of 1.5-2 mm size range were used for all coating runs. Ultra pure PVOH and citric acid were procured from Merck $^{\circledR}$ (Germany). Citric acid is used as a crosslinker between starch and $\mathrm{PVOH}$. The presence of citric acid facilitates starch and $\mathrm{PVOH}$ affinity due to intermolecular and intramolecular hydrogen bonding effectuated by $\mathrm{OH}$ functional groups of both starch and PVOH (Tang and Alavi, 2011). Tapioca starch from Kapal $A B C^{\circledR}$, Malaysia, was obtained from the local 
market. To avoid any microbial attack, it was kept in a refrigerator at $-20{ }^{\circ} \mathrm{C}$.

\section{Preparation of PVOH-modified starch solution (St- PVOH)}

The method to prepare St-PVOH coating solution was adopted from a research study reported elsewhere (Xiong et al., 2008). $5 \mathrm{~g}$ of $\mathrm{PVOH}$ was dissolved in $75 \mathrm{~mL}$ of deionized water at $90{ }^{\circ} \mathrm{C}$ with continuous agitation for $45 \mathrm{~min}$. A well mixed starch solution was separately prepared by agitating $5 \mathrm{~g}$ of Tapioca starch in $25 \mathrm{~mL}$ of deionized water at room temperature. The aqueous starch solution was added in $\mathrm{PVOH}$ solution with subsequent agitation for $1.5 \mathrm{~h}$ at $90^{\circ} \mathrm{C}$. Later on, the temperature of this solution was lowered to $30^{\circ} \mathrm{C}$ followed by the addition of aqueous citric acid solution which was prepared by dissolving $5 \mathrm{~g}$ of citric acid in $5 \mathrm{~mL}$ of deionized water at room temperature. Stirring was continued for another $1.5 \mathrm{~h}$ and the resultant StPVOH biopolymer hydrogel was allowed to cool to room temperature. The whole process was carried out in a two neck round bottom flask with a Teflon bar as an agitator. Hot plate with magnetic stirring and temperature control system was employed as a heating and mixing source.

\section{Preparation of St-PVOH coated urea (St-PCU)}

St-PCU is produced in FLP 1.5 RFBC equipment provided by Wild Horse ${ }^{\circledR}$, China. The schematic arrangement of the equipment is shown in Fig. 1. The filtered air passes through an electric heater, travels through the RFBC height and escapes from the top. The fluidizing air is suction driven from the top of RFBC by an air blower. The RFBC is equipped with a motor driven rotary disk at the bottom which facilitates the centrifugal motion of the feed granules. The fluidization of the feed granules takes place when hot air passes through the narrow channel between the rotary disk and the RFBC wall. For each sample, $200 \mathrm{~g}$ of granular urea was coated in the RFBC. The St-PVOH solution was transported into the RFBC by a peristaltic pump and sprayed into the fluidized-bed through a two-fluid nozzle.

The compressed atomizing air at elevated pressure and the ambient temperature is supplied through the two-fluid nozzle to atomize the St-PVOH solution. The fluidized-bed of the feed granules was subjected to tangential spray orientation by the adjustment of spray angle. Thermocouples are installed at the inlet, outlet and along the RFBC height to monitor the process temperature. The whole spraying operation was carried

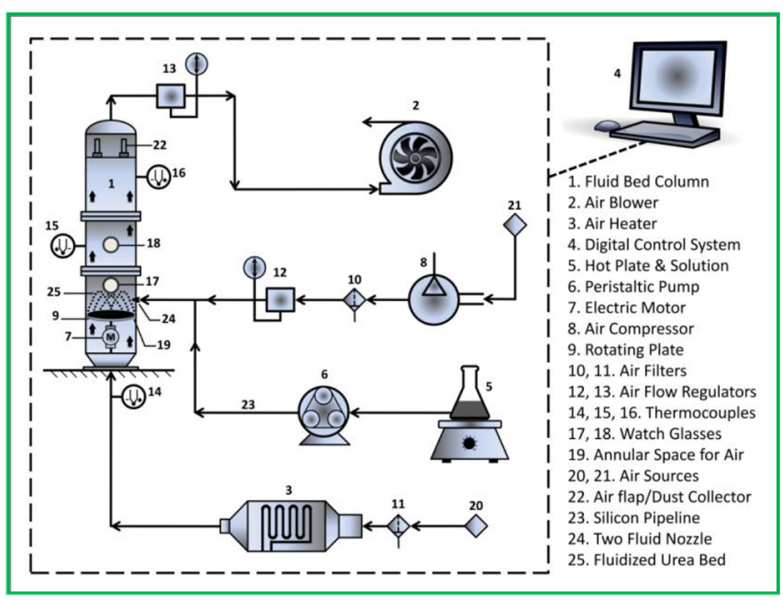

Figure 1. Schematic arrangement of rotary fluidized bed equipment for St-PCU production.

out at the steady state temperatures of the fluidizedbed and the St-PVOH solution. Pre-heating of the feed granules is accomplished during the achievement of steady state. An integrated digital controller was used to adjust and control all the process parameters involved. Since the waterborne St-PVOH solution is viscous, the concept of intermittent coating was applied to avoid excessive agglomeration and consequent collapse of the fluidized-bed (defluidization). For this purpose, all the coating runs were carried out with one min. of spray session followed by two min. of drying intervals. By the end of every coating session, the St-PCU granules were dried for $15 \mathrm{~min}$. which concludes the entire coating operation. For the impartment of better controlled-release characteristics to the end product, the St-PCU product was coated twice at the same process conditions after cleaning the equipment. The equipment is cleaned for re-coating to avoid any inconsistency of the process conditions and hydrodynamics of the fluidized bed. The final product was then subjected to various characterizations for the quality assessment.

\section{Controlled-release characteristics of St-PCU}

A Jasco V-630 UV-Vis Spectrophotometer (Japan) was used to study the urea release rate for the StPCU product in distilled water. Two grams of each coated product were immersed in $200 \mathrm{~mL}$ of double distilled water in a properly sealed environment. After time intervals of $0.5 \mathrm{~h}$, the aliquots were stirred gently with a glass rod and $3.5 \mathrm{~mL}$ of the solution was taken out for the absorbance measurement in the $\mathrm{UV}-\mathrm{Vis}$ spectrophotometer. To maintain the volume, $3.5 \mathrm{~mL}$ of distilled water was added in the aliquots after every absorbance measurement. Triplicates were 
performed and the release rates were determined by the standard curve method. The aqueous solutions of known concentrations of urea were tested in the UVVis spectrophotometer to observe the absorbance. A plot between known concentrations of urea and their corresponding absorbances was developed as shown in Fig. 2. The straight line fitting resulted in a coefficient of determination of $\mathrm{R}^{2}=0.999$ and the equation of the straight line of $y=1837 x+0.139$. Using this correlation and the absorbance data of the coated urea which was subjected to the dissolution tests, the concentration and release rates of the CRCU were determined.

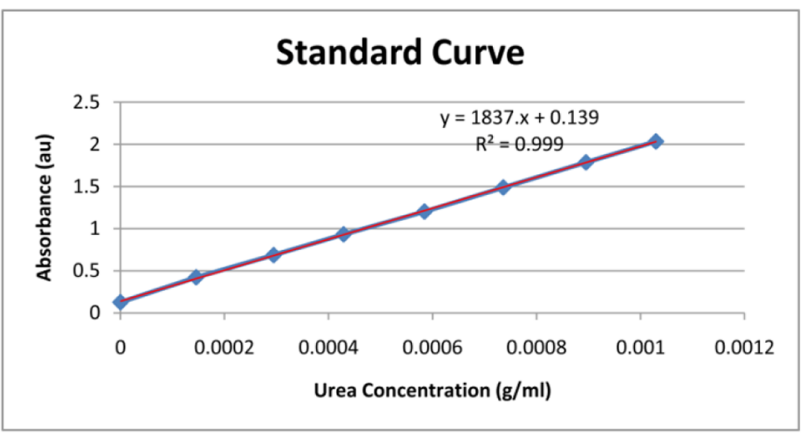

Figure 2. Standard curve for urea concentration vs absorbance.

\section{Mechanism of nutrient release from St-PCU}

The mechanism of urea release from St-PCU is studied by Peppas's empirical power law equation developed for solute release from swellable materials (Peppas, 1985). This equation has been employed in several studies (Witono et al., 2014; He et al., 2015) to investigate the release mechanism of the controlledrelease devices. According to this equation;

$$
\frac{M_{t}}{M_{\infty}}=k t^{n}
$$

where $M_{t} / M_{\infty}$ is the fraction of active nutrient (urea) released in time $t, n$ is the diffusional parameter indicative of the release and the transport mechanism and $k$ is a constant which incorporates the characteristics of the coating and the active nutrient. A plot between $\ln \left(M_{t} / M_{\infty}\right)$ and $\ln (t)$ produces a straight line and the values of $n \& k$ were estimated by the least square method. Further details of this method can be referred from the literature (Peppas, 1985).

\section{Coating uniformity of St-PCU}

Various methods including the measure of standard deviation of coating thickness (Lubkowski et al., 2015; Tobiska and Kleinebudde, 2003; Depypere et al., 2009), coating mass variance (Dhaese 2014), and ratio of coating mass to particle surface area (Lustrik et al.,
2012) are reported to determine coating uniformity. This study utilized the coefficient of variance (CV) of coating thickness. For this purpose, a Field Emission Scanning Electron Microscope (FESEM) by Zeiss Supra $55 \mathrm{VP}^{\circledR}$ (Germany) integrated with Energy Dispersive X-Ray Spectrometer (EDX) INCAx-act ${ }^{\circledR}$, Oxford Instruments (United Kingdom) was used to determine coating thicknesses of CRCU precisely. 5 granules were randomly picked from each sample and cut with a sharp knife to get the cross sections. One cross section was examined from 40 different equally spaced points to measure coating thickness. Thus, 200 data points of coating thickness are obtained for one sample and 10,000 data points for 50 samples to investigate the effect of process variables on coating uniformity.

\section{Experimental design and process optimization}

Response surface methodology (RSM) was employed for the experimental design and process optimization. For this purpose, the central composite rotatable design (CCRD) was chosen using Design Expert $^{\mathbb{B}}$ 8.0. The process variables include atomizing air pressure (A), fluidizing gas temperature (B), spray rate $(C)$, spray temperature $(D)$, and coating time $(E)$. Several trial runs were performed earlier to investigate the minimum and maximum values of the process variables. The minimum values recorded were 0.5 bar, $50{ }^{\circ} \mathrm{C}, 0.5 \mathrm{RPM}(0.02 \mathrm{~mL} / \mathrm{s}), 70^{\circ} \mathrm{C}$, and $30 \mathrm{~min}$., respectively, for A, B, C, D, and E. Similarly, the maximum values recorded were 4.0 bar, $120{ }^{\circ} \mathrm{C}, 5.0$ $\mathrm{RPM}(0.2 \mathrm{~mL} / \mathrm{s}), 100{ }^{\circ} \mathrm{C}$, and $150 \mathrm{~min}$, respectively, for $\mathrm{A}, \mathrm{B}, \mathrm{C}, \mathrm{D}$, and $\mathrm{E}$. The CCRD generated 50 experimental runs with 8 central points (replicate runs). The results were fitted to the model for each response and the model significance was evaluated by the analysis of variance (ANOVA).

\section{RESULTS AND DISCUSSION}

\section{Controlled-release characteristics of St-PCU}

The release performance of all the CRCU samples is presented in Table 1. In this Table, $\mathrm{T}_{100}, \mathrm{~T}_{75}$, and $\mathrm{T}_{50}$ represent time needed for $100 \%, 75 \%$, and $50 \%$ release of nitrogen respectively. The ANOVA results for the effect of different process parameters on the release time of the St-PCU are given in Table 2. The p-Value less than 0.05 indicates model terms are significant. In this case, $\mathrm{B}, \mathrm{E}, \mathrm{B} 2, \mathrm{C} 2$ are significant model terms. The terms $\mathrm{BC}, \mathrm{BD}, \mathrm{BE}$ and $\mathrm{DE}$ can be regarded as marginally significant because of the 
relatively low $\mathrm{p}$-Values. The most influential process parameters appear to be coating time and the fluidizing gas temperature. The value of the regression coefficient $\mathrm{R}^{2}=0.9105$ indicates that the model can be fitted to the experimental results with acceptable precision. The Adj. $\mathrm{R}^{2}$ value of 0.8488 is in agreement with the value of the regression coefficient, $\mathrm{R}^{2}$. The model equation for the release time in terms of significant and marginally significant coded variables is presented as follows.

Release Time $=15.08-1.13 B+1.39 E+0.48 B C$

$-0.5 B D-0.68 B E+0.51 D E-8.66 B^{2}-3.61 C^{2}$

To explain the interactive effect of different process variables on release time, only the statistically significant or marginally significant terms are considered. In Fig. 3a, the response surface shows that the release time initially increases and gets to a maximum with the combined increase in both the fluidizing gas temperature and the spray rate. The highest release time is achieved at the conditions near the center points at a gas temperature around 80 ${ }^{\circ} \mathrm{C}$ and a spray rate of 2.75 RPM. After a maximum point, the release time keeps on decreasing with further increase in fluidizing gas temperature and spray rate. This happens because the spray droplets initially collide with the granules' surface followed by wetting and droplet spreading by the coalescence of the microdroplets. The hot fluidizing gas reduces the solution viscosity facilitating the droplets' spreading, increases the bed mobility (De Oliveira et al., 1997) and causes dewatering of the spread droplets, forming a thin coating film. The cycle continues until a uniform and compact film is formed, which results in prolonged release when subjected to dissolution test. However, at high temperature the spray droplets experience premature drying before hitting the granules' surface and are carried away with the fluidizing gas, which is called elutriation (Donida and Rocha, 2002; da Rosa and dos Santos Rocha, 2010). Some of the droplets collide and wet the granule surface but dry before spreading and, therefore, appear as tiny solid spheres on the granules' surface, forming a porous and irregular coating film (Lan et al., 2011). Fig. 4 shows a pictorial comparison of the St-PCU granules with regular and irregular films. The elutriated particles formed a significant quantity of dust at high temperature, which could be observed on the machine walls and the exhaust duct after the experiments.

In addition to elutriation and poor spreading of the spray droplets, the spray solution dries at the tip of the spray nozzle at higher temperature causing partial blockade and abnormal spray orientation which gives rise to preferential coating. Elutriation does not only take place due to pre-mature drying of droplets but also due to prolonged exposure of coated granules at high temperature, which distorts the fragile coating layer due to attrition within the fluidized bed.

On the other hand, as the spray rate increases beyond a certain level, the droplets' size increases, which leads to the lower dewatering capacity of the fluidizing gas. Consequently, a coarse and porous coating film is formed with inferior controlled-release characteristics. It has also been observed that a volume of spray solution is lost on the machine walls at high spray rate. This spray loss is responsible for a thin film which cannot withstand the osmotic pressure of the dissolved nutrient inside the coating layer and hence, the release time is relatively low. In such cases, some of the granules stick to the machine wall for quite some time, which may either reduce the frequency of their projection in the spray zone or they can constantly stay in the spray zone. The former situation may lead to lower coating thickness and the latter may result in a coarse and porous coating layer with imperfect zones. The spray loss also takes place at a low fluidizing temperature and high spray rate. In such conditions, relatively bigger spray droplets were observed sticking to the walls of the fluidized bed. The statistical analysis suggests that fluidizing gas temperature is more influential than the spray rate, as portrayed in Fig. 3a.

These results are in synchrony with the literature. Ayub et al. (2001) attributed fluidizing gas temperature as the principal factor controlling urea dissolution. Rosa et al. (2013) reported that both high and low temperatures were not suitable for particle growth during urea coating using vinasse as a coating material. Donida et al. (2002) suggested to investigate the optimum process conditions as none of the high and low conditions of fluidizing gas temperature produced promising results for controlled-release urea prepared using an aqueous polymeric solution. Tsai et al. (1986) reported extended release time with increasing fluidizing gas temperature with a minimum dissolution at $80{ }^{\circ} \mathrm{C}$. Above this temperature, the release time started decreasing. This is compatible with the results of the current study although the coating material in both cases is different. Weiss et al. (1983) also concluded that the coating quality of controlledrelease urea improved up to $80^{\circ} \mathrm{C}$ of fluidizing gas temperature and decreased above that. Higher spray rate is reported to result in lower release time (Salman 1988), rough (Donida and Rocha, 2002), loose and porous coating film (Lan et al., 2011), and loss of 


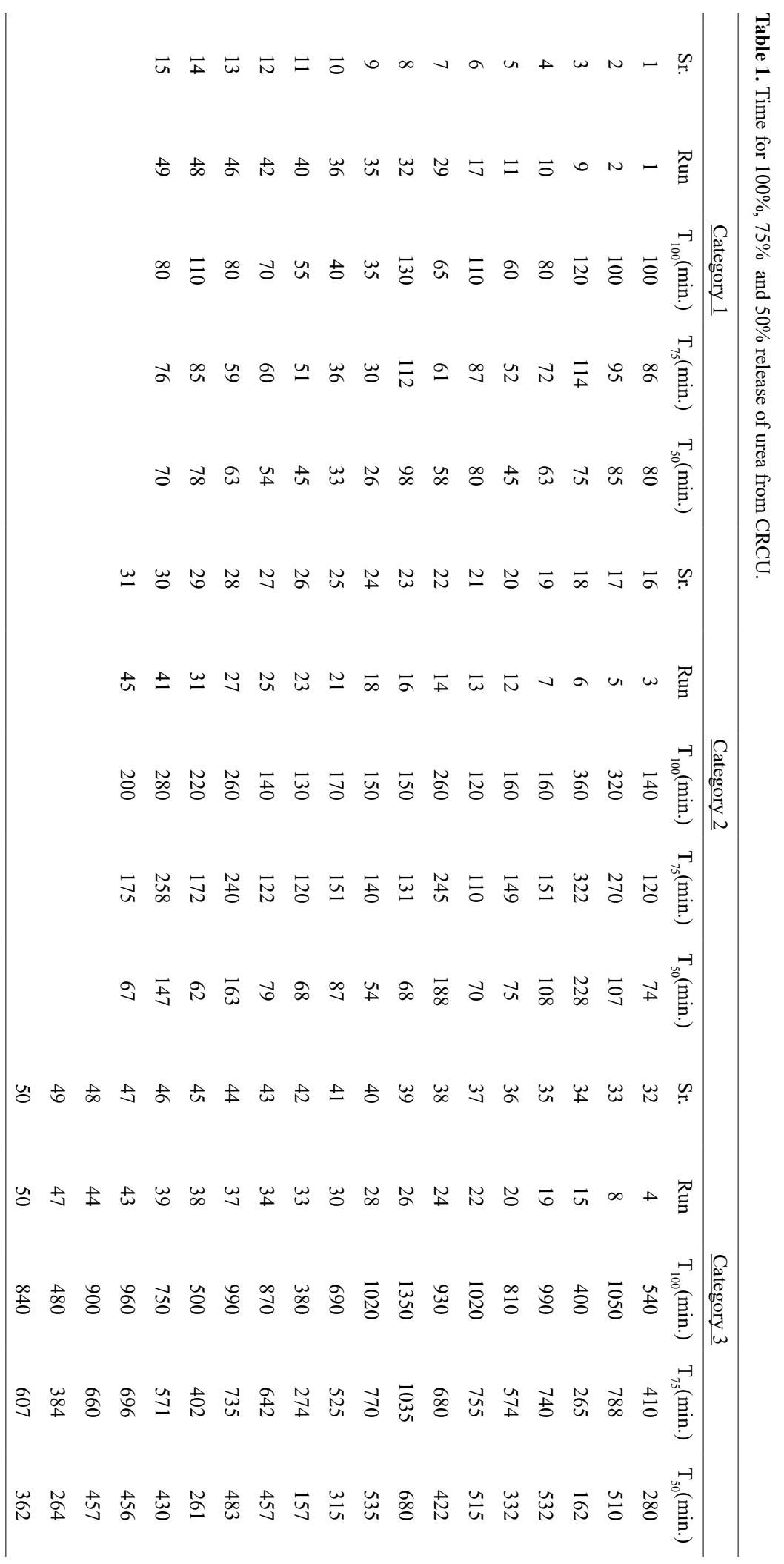


Table 2. ANOVA results for the effect of process variables on release time \& CV of coating thickness.

\begin{tabular}{|c|c|c|c|c|}
\hline \multirow{2}{*}{ Source } & \multicolumn{2}{|c|}{ Release Time } & \multicolumn{2}{|c|}{ CV of Coating Thickness } \\
\hline & Sum of Squares & p-Value & Sum of Squares & p-Value \\
\hline Model & 1715.88 & $<0.0001$ & 2044.12 & $<0.0001$ \\
\hline A & 0.096 & 0.8987 & 269.82 & $<0.0001$ \\
\hline B & 43.53 & 0.0105 & 22.04 & 0.1578 \\
\hline $\mathrm{C}$ & 0.46 & 0.7796 & 10.72 & 0.3202 \\
\hline $\mathrm{D}$ & 6.30 & 0.3065 & 64.88 & 0.0188 \\
\hline $\mathrm{E}$ & 65.36 & 0.0022 & 33.85 & 0.0828 \\
\hline $\mathrm{AB}$ & 0.21 & 0.8511 & 175.04 & 0.0003 \\
\hline $\mathrm{AC}$ & 0.026 & 0.9469 & 0.73 & 0.7934 \\
\hline $\mathrm{AD}$ & 0.22 & 0.8480 & 135.80 & 0.0012 \\
\hline $\mathrm{AE}$ & 0.00118 & 0.9887 & 0.73 & 0.7943 \\
\hline $\mathrm{BC}$ & 7.32 & 0.2711 & 262.38 & $<0.0001$ \\
\hline $\mathrm{BD}$ & 7.86 & 0.2545 & 36.54 & 0.0720 \\
\hline $\mathrm{BE}$ & 14.93 & 0.1199 & 0.63 & 0.8076 \\
\hline $\mathrm{CD}$ & 0.063 & 0.9180 & 15.36 & 0.2358 \\
\hline $\mathrm{CE}$ & 0.55 & 0.7607 & 4.92 & 0.4988 \\
\hline $\mathrm{DE}$ & 8.31 & 0.2417 & 0.83 & 0.7810 \\
\hline $\mathrm{A}^{2}$ & 2.06 & 0.5567 & 6.00 & 0.4553 \\
\hline $\mathrm{B}^{2}$ & 185.57 & $<0.0001$ & 38.79 & 0.0643 \\
\hline $\mathrm{C}^{2}$ & 32.17 & 0.0257 & 5.26 & 0.4842 \\
\hline $\mathrm{D}^{2}$ & 0.86 & 0.7041 & 10.39 & 0.3277 \\
\hline$E^{2}$ & 0.033 & 0.9403 & 4.55 & 0.5151 \\
\hline Residual & 168.67 & & 303.97 & \\
\hline Lack of Fit & 162.89 & 0.0031 & 303.20 & $<0.0001$ \\
\hline Pure Error & 5.78 & & 0.77 & \\
\hline R-Squared ( $\left.{ }^{2}\right)$ & 0.9105 & & 0.8705 & \\
\hline Adjusted $\mathrm{R}^{2}$ & 0.8488 & & 0.7813 & \\
\hline Predicted $\mathrm{R}^{2}$ & 0.6980 & & 0.5101 & \\
\hline
\end{tabular}

coating suspension (da Rosa and dos Santos Rocha, 2013). All these results are consistent with the results of the current study.

Fig. $3 \mathrm{~b}$ portrays the interactive effect of spray temperature and fluidizing gas temperature on the release time. There is an increasing trend of release time with the combined increment of both the process variables and then a consistent decrease with further increase. This is because initially there is a gradual increase of coating thickness, which results in higher release time. After a particular temperature, distortion of the coating layer starts due to poor droplet spreading, thin coating layer, and spray loss due to elutriation. The fluidizing gas temperature affects more significantly than the spray temperature.

The response surface in Fig. 3c represents the interactive effect of coating time and spray temperature on release time. It is observed that the release time increases with an integrated increase of both the process variables. The statistical analysis reveals that coating time is much influential as compared to spray temperature. With extended process time, the thickness of coating layer increases, which plays an important role for the impediment of the dissolved nutrient escape from within the coating shell. This is in synchrony with the results of Oliveira et al. (1997) and Pissinati et al. (2003), who suggested that the coating mass increases linearly with coating time. The longer coating time also facilitates the granules to have a more compact coating layer incorporated by the rolling motion of the granules on the rotary plate of RFBC.

The interactive effect of coating time and fluidizing gas temperature on release time is shown in Fig. 3d. It is observed that the release time increases with an increase in both the process variables followed by a sharp decrease. Coating thickness keeps on increasing with time at moderately high temperature, but beyond that, higher temperature causes elutriation, spray loss, 

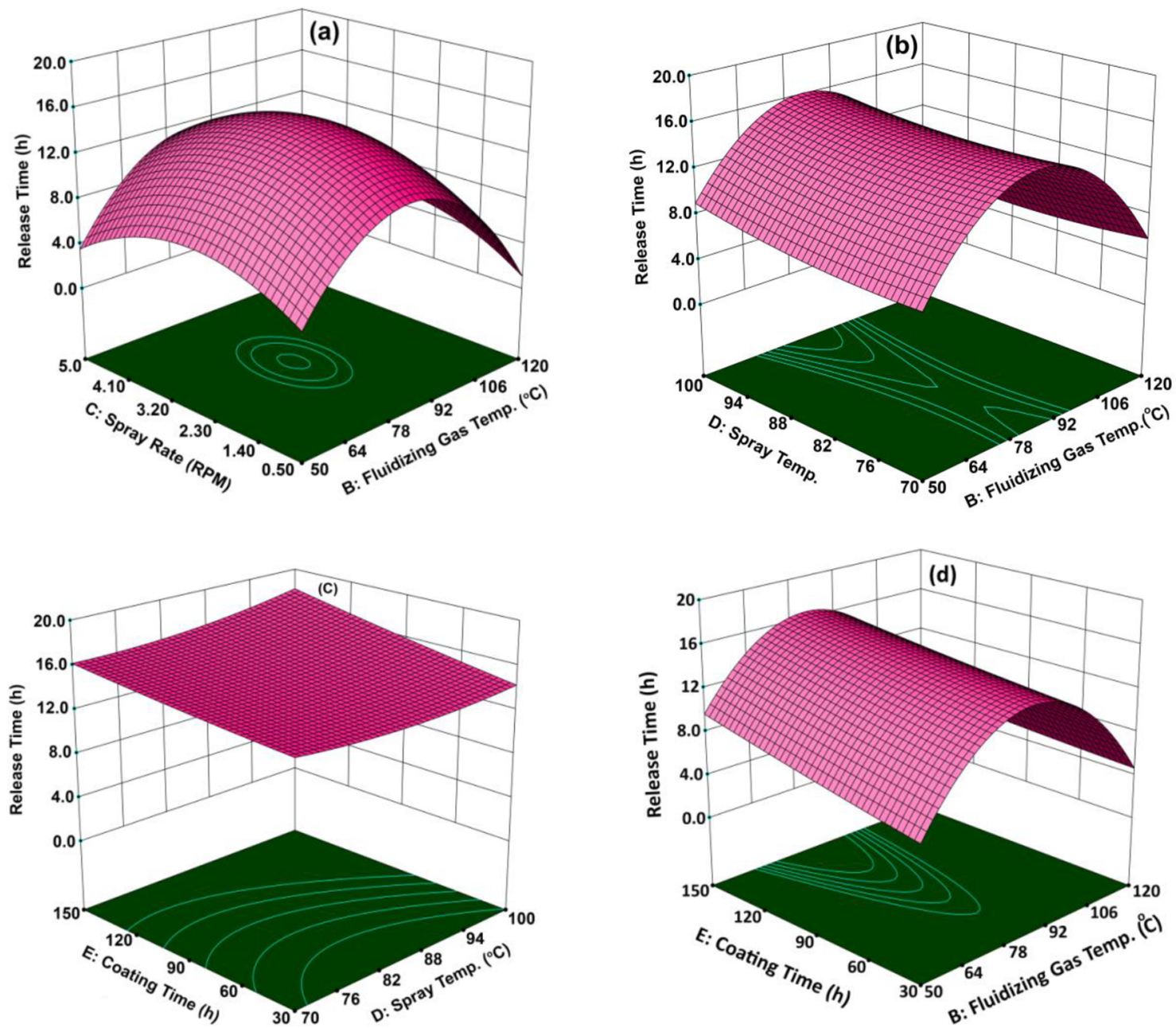

Figure 3. Response surfaces for the interactive effect of (a) fluidizing gas temperature \& spray rate, (b) fluidizing gas temperature \& spray temperature, (c) coating time \& spray temperature, and (d) coating time \& fluidizing gas temperature, on urea release time.

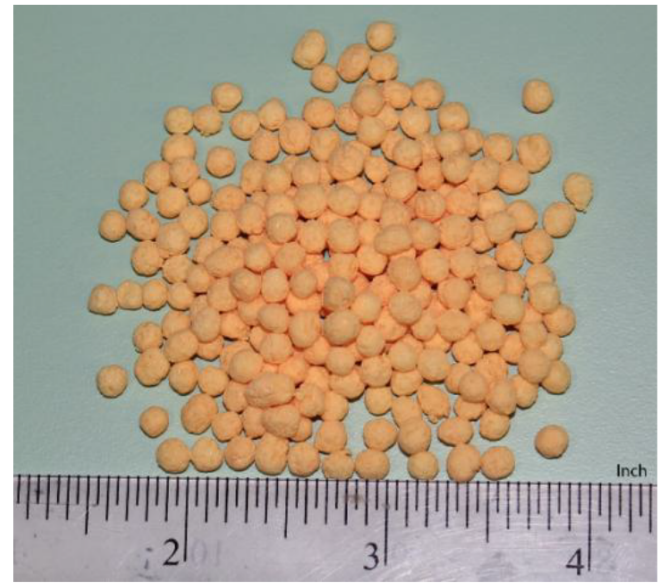

a)

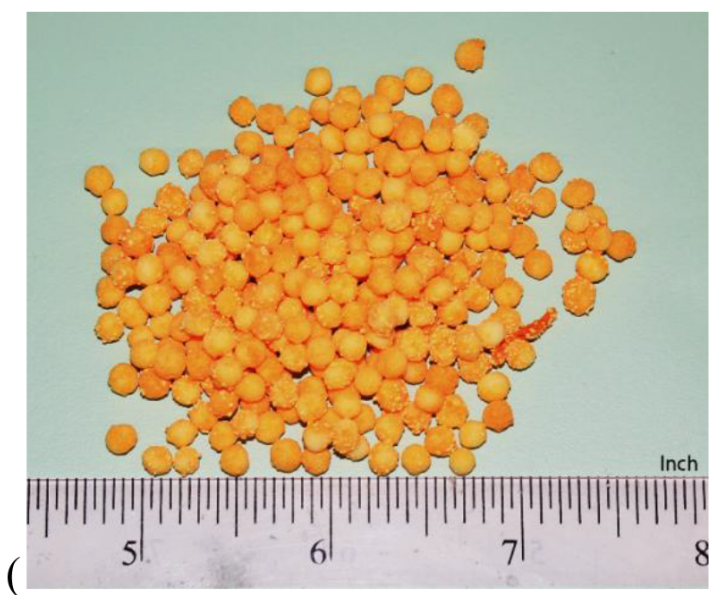

(b)

Figure 4. Photographic view of (a) St-PCU with uniform coating and (b) St-PCU with distorted coating layer having dried solid particles on the surface. 
poor spreading, and development of a thin coating layer which are responsible for a lower release time.

Although the release characteristics of the St-PCU are not compatible with the European Standard (EN 13266, 2001) according to which the controlledrelease fertilizer should not release more than $15 \%$ of the active nutrient within first $24 \mathrm{~h}$., a comparison of the starch based CRU given in Table 3 shows that the release time of St-PCU produced in this study has either better or comparable release time. The maximum release time achieved in this study is $22.667 \mathrm{~h}$. and the minimum is $0.556 \mathrm{~h}$.

From the ANOVA analysis, a plot of actual versus predicted values of the release time is shown in Fig. 5a. It can be observed that most of the points lie near the straight line indicating better fit. The optimum values of process and response variables for release time obtained from the statistical analysis are given in Table 4. Using these optimum values, triplicates of the confirmation runs were performed and the results are presented in Table 4.

\section{Mechanism of nutrient release from St-PCU}

The investigation of the release mechanism is imperative to design the new controlled-release fertilizers and choose the coating material of desired controlled-release characteristics (Ni et al., 2011). The transport of active nutrient through the macromolecular structure, especially when the coating material is inclined to swell, is a complex process. In this study, the mechanism of urea release from St-PCU is studied by Peppas's empirical power law designed for solute release from swellable materials (Peppas, 1985). The model constants, $n$ and $k$ obtained by applying the least square method after plotting $\ln \left(M_{t} / M_{\infty}\right)$ and $\ln (t)$ along with the coefficient of regression $\left(\mathrm{R}^{2}\right)$ and root mean square error (RMSE) for all 50 runs, are given in Table 5. The values of diffusion exponent ' $n$ ' are given in an increasing order.
It can be observed in Table 5 that all the samples bear the $n$ value greater than 0.45 . In case, $n \leq 0.45$, the nutrient transport is supposed to be governed by Fickian diffusion. The driving force for the nutrient diffusion from the granule core across the swelled polymer coating layer is controlled by the concentration gradient only. For the Fickian transport, it is believed that the nutrient release is much slower than the polymer chains' relaxation. The polymer chain relaxation involves large scale motion or changes in the polymer chain structure. For $0.45<n<0.89$, the nutrient transport is governed by the dynamic swelling and macromolecular chain relaxation. In such case, the nutrient diffusion in or out of the swollen polymer chains is comparable to the relaxation rate, that is, the nutrient release is governed by the combination of diffusion and polymer relaxation. The solute diffusion in the polymer wall and solute dissolution into the main water body take place simultaneously. It is reported that the nutrient transport in most of the superabsorbent hydrogels follows this transport phenomenon that is also termed non-Fickian or anomalous diffusion. For $n$ $>0.89$, the nutrient release is called Case-II transport for which solely molecular relaxation is responsible for nutrient transport (Witono et al., 2014; He et al., 2015).

Since the $n$ value for all our samples is above 0.45 , none of the samples obeyed the Fickian diffusion for the transport of their active nutrient. Hence, the driving force for the nutrient release was not solely the concentration gradient. For samples from Sr. 1-12, since the $n$ value is up to 0.89 , it can be said that nutrient release for these samples followed non-Fickian or anomalous diffusion. In this case, the nutrient transport took place by the combination of nutrient diffusion and polymer relaxation. For the rest of the cases, a Case-II transport is witnessed because of the $n$ value greater than 0.89 . It can be observed from Table 5 and the nutrient release data that there is a general

Table 3. Release time of controlled release urea prepared using biomaterial/allied coatings.

\begin{tabular}{lcc}
\hline References & Coating material & Release Time (h) \\
\hline Naz and Sulaiman (2014) ) & Starch/urea/borate & 0.055 \\
Tomaszewska and Jarosiewicz (2004) & Starch/polysulfone & 5.0 \\
Lum et al. (2016) & Starch/boric acid/polyvinyl alcohol & 8.0 \\
Ito et al. (2003) & Starch/paraffin wax & $1.0-13.33$ \\
Zhao et al. (2016) & Starch/natural rubber & 15.0 \\
Chen et al. (2008) & Starch/poly-lactide & $8.0-26.0$ \\
Riyajan et al. (2012) & Starch/natural rubber & 24.0 \\
Niu and Li (2012) & Starch/polyvinyl acetate & 28.0 \\
Rychter et al. (2016) & Starch/glycerol/urea & 32.0
\end{tabular}


Table 4. Optimum predicted values of process and response variables (from ANOVA), mean values of actual response variables (from confirmation runs) and $\%$ error after triplicates performed.

\begin{tabular}{|c|c|c|c|c|c|c|c|c|}
\hline \multirow[b]{2}{*}{$\begin{array}{l}\text { Response } \\
\text { variables }\end{array}$} & \multicolumn{5}{|c|}{ Optimum predicted process variables } & \multirow{2}{*}{$\begin{array}{l}\text { Optimum } \\
\text { predicted } \\
\text { response } \\
\text { variables }\end{array}$} & \multirow{2}{*}{$\begin{array}{l}\text { Mean values } \\
\text { of actual } \\
\text { response } \\
\text { variables from } \\
\text { confirmation } \\
\text { runs }\end{array}$} & \multirow[b]{2}{*}{$\%$ Error $(\%)$} \\
\hline & $\begin{array}{l}\text { Atomizing air } \\
\text { pressure A bar }\end{array}$ & $\begin{array}{c}\text { Fluidizing gas } \\
\text { temperature } \\
\mathrm{B}^{\circ} \mathrm{C}\end{array}$ & $\begin{array}{c}\text { Spray rate C } \\
\text { RPM }\end{array}$ & $\begin{array}{c}\text { Spray } \\
\text { temperature } \\
\mathrm{D}^{\circ} \mathrm{C}\end{array}$ & $\begin{array}{l}\text { Coating time } \\
\text { E min. }\end{array}$ & & & \\
\hline Release time & 0.23 & 80.34 & 2.71 & 85 & 150 & $18.26 \mathrm{~h}$ & $17.07 \mathrm{~h}$ & $6.02 \%$ \\
\hline $\begin{array}{l}\mathrm{CV} \text { of coating } \\
\text { thickness }\end{array}$ & 0.30 & 83.09 & 2.46 & 87.31 & 52.2 & $11.41 \%$ & $10.46 \%$ & $5.54 \%$ \\
\hline
\end{tabular}

trend of increment in the $n$ value for samples having low release time. This may be because of the higher degree of chain relaxation which led to the formation of distorted polymer chains that could not sustain the nutrient for a long time. The microscopic image of one such coating shell is shown in Fig. 5. Hence, polymer relaxation was the sole phenomenon to govern the nutrient release for samples having values greater than 0.89 . On the contrary, it is observed that most of the samples having relatively higher release time bear low $n$ values for the nutrient transport. This may be due to the formation of a stable network of swollen polymer chains for which the nutrient transport follows both diffusion and polymer relaxation.

All these findings are in accordance to the literature, according to which the nutrient transport in almost all the superabsorbent hydrogels is governed solely by the polymer relaxation (Witono et al., 2014; He et al., 2015). For example, Witono et al. studied water diffusion in starch/polyacrylic acid films for different degrees of neutralization and it was found that, in most of the cases, the transport was governed by non-Fickian diffusion (Witono et al., 2014). This vindicates the findings of the current study. The value of the regression coefficient, $\mathrm{R}^{2}$, in most of the cases is above 0.95 (Table 5), which indicates a good fit of the empirical power law with the experimental data.

To further explain the release mechanism, the release data of all the samples are classified into three categories as shown in Table 1. It can be observed in Table 1 for run 2 (Category 1) that it takes $85 \mathrm{~min}$. for urea to have $50 \%$ release, whereas the rest of the $50 \%$ is released in just $15 \mathrm{~min}$. This means that the swollen polymer membrane sustained the osmotic pressure of the dissolved nutrient inside the core of the granule for $85 \mathrm{~min}$. followed by a burst release, which is likely to happen due to some coating imperfections as displayed in Fig. 6. At the point of coating imperfection, the osmotic pressure dominates the polymer chains resistance and the coating film rupture causes a spontaneous release. Similarly, it can be observed in Table 1 for run 3 (Category 2) that it takes $2 \mathrm{~h}$ for $75 \%$ release of urea from this sample, but the rest of the 25 $\%$ was released in only $20 \mathrm{~min}$. This may also be due
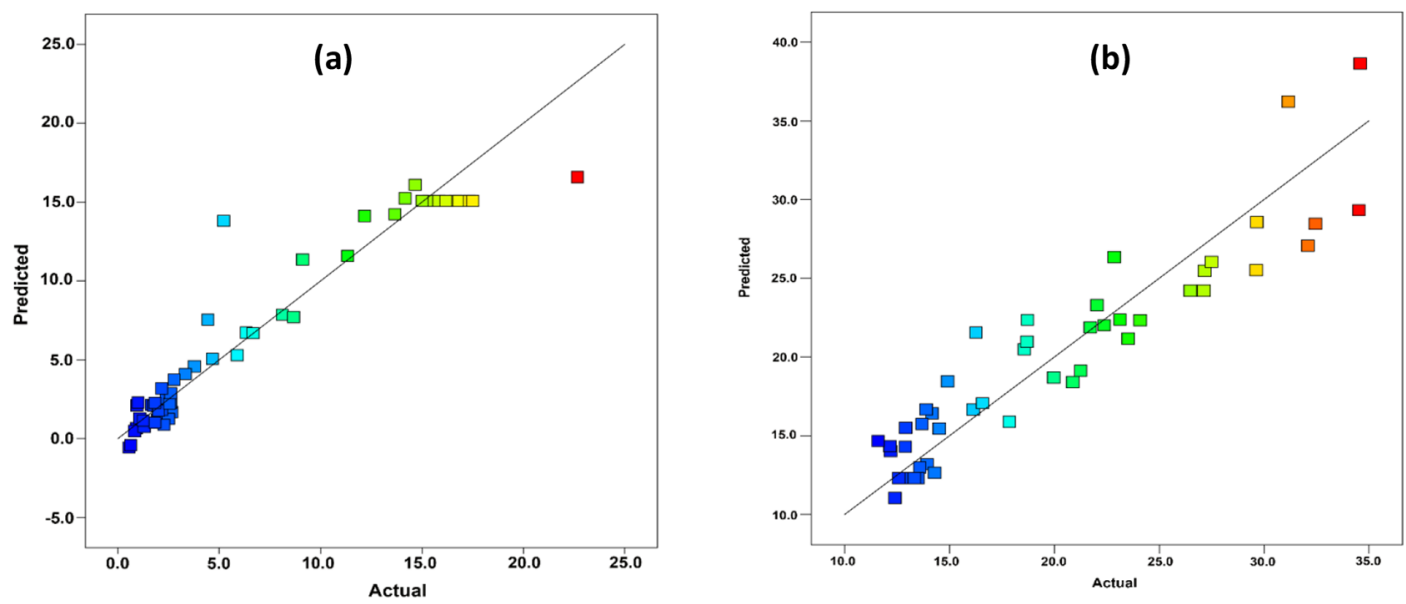

Figure 5. Actual vs predicted values for (a) Release time, (b) CV of coating thickness 
Table 5. Values of kinetic parameters ( $n$ and $k$ ), regression coefficient, $\mathrm{R}^{2}$, and RMSE.

\begin{tabular}{|c|c|c|c|c|c|c|c|c|c|c|c|}
\hline $\mathrm{Sr}$ & Run & $n$ & $k$ & $\mathrm{R}^{2}$ & RMSE & $\mathrm{Sr}$ & Run & $n$ & $K$ & $\mathrm{R}^{2}$ & RMSE \\
\hline 1 & 18 & 0.531 & 6.077 & 0.973 & 5.10 & 26 & 44 & 0.988 & 0.124 & 0.997 & 1.31 \\
\hline 2 & 31 & 0.550 & 4.810 & 0.959 & 5.61 & 27 & 28 & 0.988 & 0.106 & 0.998 & 0.97 \\
\hline 3 & 45 & 0.596 & 3.733 & 0.967 & 5.31 & 28 & 4 & 0.994 & 0.191 & 0.994 & 1.94 \\
\hline 4 & 5 & 0.601 & 2.884 & 0.977 & 4.86 & 29 & 47 & 1.004 & 0.198 & 0.995 & 2.15 \\
\hline 5 & 9 & 0.640 & 3.452 & 0.873 & 9.24 & 30 & 19 & 1.044 & 0.076 & 0.997 & 1.45 \\
\hline 6 & 32 & 0.655 & 2.885 & 0.837 & 10.11 & 31 & 3 & 1.051 & 0.513 & 0.994 & 3.22 \\
\hline 7 & 12 & 0.722 & 2.141 & 0.978 & 5.24 & 32 & 38 & 1.053 & 0.141 & 0.974 & 2.04 \\
\hline 8 & 23 & 0.806 & 1.676 & 0.968 & 5.44 & 33 & 7 & 1.065 & 0.368 & 0.98 & 5.67 \\
\hline 9 & 41 & 0.820 & 0.835 & 0.987 & 5.04 & 34 & 39 & 1.087 & 0.076 & 0.996 & 1.36 \\
\hline 10 & 15 & 0.873 & 0.562 & 0.975 & 3.98 & 35 & 27 & 1.105 & 0.189 & 0.992 & 4.34 \\
\hline 11 & 6 & 0.883 & 0.483 & 0.96 & 7.17 & 36 & 13 & 1.148 & 0.373 & 0.988 & 3.95 \\
\hline 12 & 20 & 0.894 & 0.259 & 0.982 & 2.18 & 37 & 17 & 1.168 & 0.362 & 0.882 & 9.00 \\
\hline 13 & 34 & 0.904 & 0.219 & 0.979 & 2.04 & 38 & 25 & 1.204 & 0.254 & 0.995 & 3.84 \\
\hline 14 & 50 & 0.910 & 0.226 & 0.991 & 2.02 & 39 & 1 & 1.250 & 0.287 & 0.938 & 8.47 \\
\hline 15 & 37 & 0.924 & 0.170 & 0.997 & 0.95 & 40 & 48 & 1.319 & 0.167 & 0.93 & 8.06 \\
\hline 16 & 33 & 0.924 & 0.422 & 0.992 & 2.54 & 41 & 14 & 1.324 & 0.054 & 0.967 & 6.22 \\
\hline 17 & 21 & 0.927 & 0.799 & 0.983 & 4.73 & 42 & 11 & 1.447 & 0.244 & 0.978 & 6.87 \\
\hline 18 & 24 & 0.929 & 0.177 & 0.996 & 1.06 & 43 & 10 & 1.474 & 0.137 & 0.973 & 8.50 \\
\hline 19 & 16 & 0.930 & 0.891 & 0.927 & 4.85 & 44 & 46 & 1.474 & 0.137 & 0.973 & 8.50 \\
\hline 20 & 30 & 0.934 & 0.223 & 0.992 & 2.19 & 45 & 36 & 1.524 & 0.308 & 0.96 & 8.96 \\
\hline 21 & 8 & 0.937 & 0.148 & 0.995 & 1.40 & 46 & 40 & 1.715 & 0.086 & 0.962 & 7.92 \\
\hline 22 & 2 & 0.962 & 0.892 & 0.87 & 10.84 & 47 & 35 & 1.768 & 0.171 & 0.983 & 6.34 \\
\hline 23 & 26 & 0.979 & 0.086 & 0.996 & 1.15 & 48 & 49 & 1.783 & 0.036 & 0.955 & 9.65 \\
\hline 24 & 43 & 0.980 & 0.123 & 0.981 & 1.27 & 49 & 29 & 1.814 & 0.046 & 0.95 & 8.35 \\
\hline 25 & 22 & 0.987 & 0.109 & 0.993 & 1.13 & 50 & 42 & 2.397 & 0.003 & 0.95 & 6.57 \\
\hline
\end{tabular}
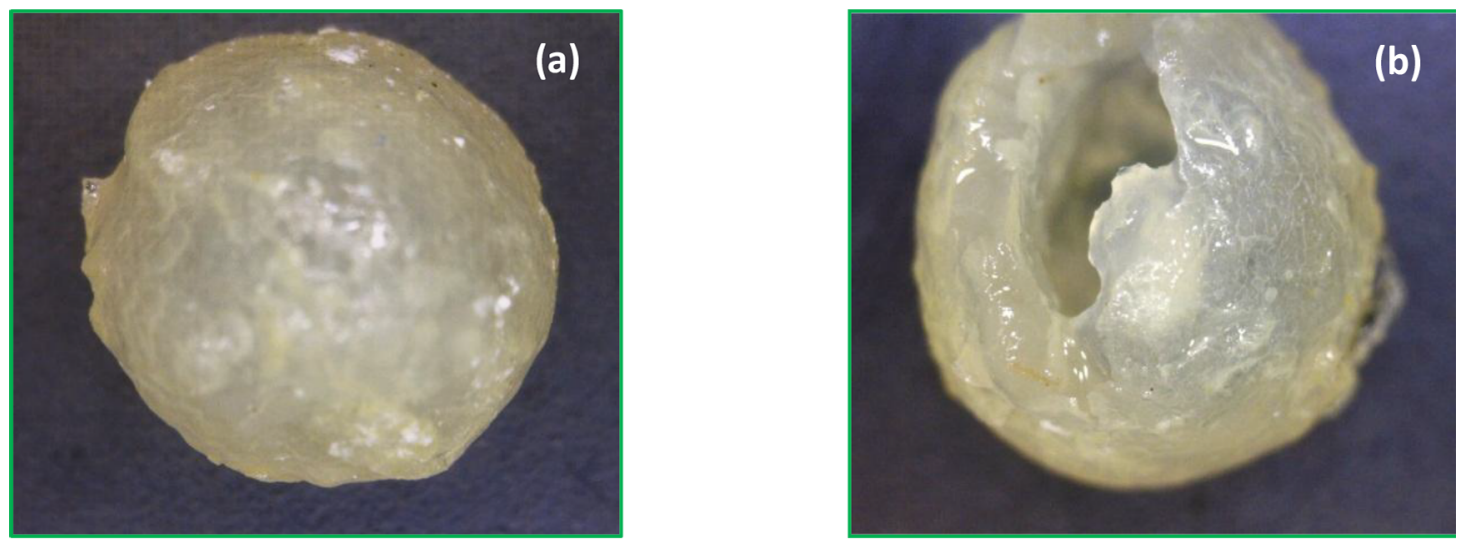

Figure 6. Microscopic photos of (a) Swollen and intact coating shell and (b) swollen and distorted coating shell of St-PCU granules.

to the presence of cracks and coating heterogeneities which withstood the osmotic pressure for quite some time followed by the spontaneous release. The third category, which is attributed as the superior of these two, includes all the rest of the samples in which this kind of behavior is not witnessed, that is, the spontaneous release of the nutrient is not observed for the rest of the samples represented under category 3 in Table 1.

\section{Coating uniformity of St-PCU}

The ANOVA results for the effect of different process parameters on the coefficient of variance of the coating thickness of the St-PCU are given in Table 2. In this case $A, D, A B, A D, B C$, and $B D$ are the significant model terms. The terms $\mathrm{B}, \mathrm{E}, \mathrm{BD}$, and $\mathrm{B}^{2}$ can be regarded as marginally significant because of the relatively low $\mathrm{p}$-Values. The most influential process 
parameters appear to be the atomizing air pressure and the combination of fluidizing gas temperature \& spray rate. The value of the regression coefficient, $\mathrm{R}^{2}=0.8705$, indicates that the model can be fitted to the experimental results with acceptable precision. The Adj. $R^{2}$ value of 0.7813 is in agreement with the value of the regression coefficient, $\mathrm{R}^{2}$. The model equation for the coefficient of variance of coating thickness in terms of significant and marginally significant coded variables is presented as follows.

$$
\begin{aligned}
& \text { CV of Coating thickness }=12.30-2.82 A+ \\
& 0.81 B+1.38 D+1.00 E-2.34 A B-2.06 A D^{-} \\
& 2.86 B C+1.07 B D^{-}-0.69 C D+3.96 B^{2}
\end{aligned}
$$

The FESEM micrograph of a St-PCU cross section is given in Fig. 7. Forty thickness points have been chosen for one granule to report coating uniformity. To study the effect of process parameters on coating uniformity in detail, the response surfaces are presented herewith. From Fig. 8a, it is observed that at the highest fluidizing gas temperature and lowest atomizing pressure, the $\mathrm{CV}$ of coating thickness is highest, indicating the lowest uniformity. This is because of premature drying and poor spreading of spray droplets at a high gas temperature and rough \& porous coating that results at low atomizing pressure because of the generation of bigger droplets. At the highest atomizing pressure and lowest gas temperature, the $\mathrm{CV}$ of coating thickness is moderately high. The higher atomizing pressure not only produces very small spray droplets (Paulo Filho et al., 2006) but also helps for the impingement and spreading of spray droplets due to its momentum, which consequently increases the surface area and hence facilitates the solvent evaporation (Tobiska and Kleinebudde, 2003). However, this advantage can only be achieved if there is sufficient gas temperature for the solvent to evaporate from these tiny droplets. A low gas temperature not only causes delayed evaporation of the droplets, but also facilitates the formation of temporary aggregates of the granules, which results in a rough and porous coating after they detach from each other once the liquid bridge between them is broken due to solvent evaporation. As a result of this phenomenon, the coating uniformity is disturbed. At the lowest gas temperature and lowest atomizing pressure, the CV of thickness is relatively high, but lower than the previous two cases. Similarly, at the maximum values of both of these process variables, the $\mathrm{CV}$ is high but definitely lower than the first two cases. So it can be concluded that the extreme conditions of gas temperature and atomizing pressure have a negative effect on coating uniformity.

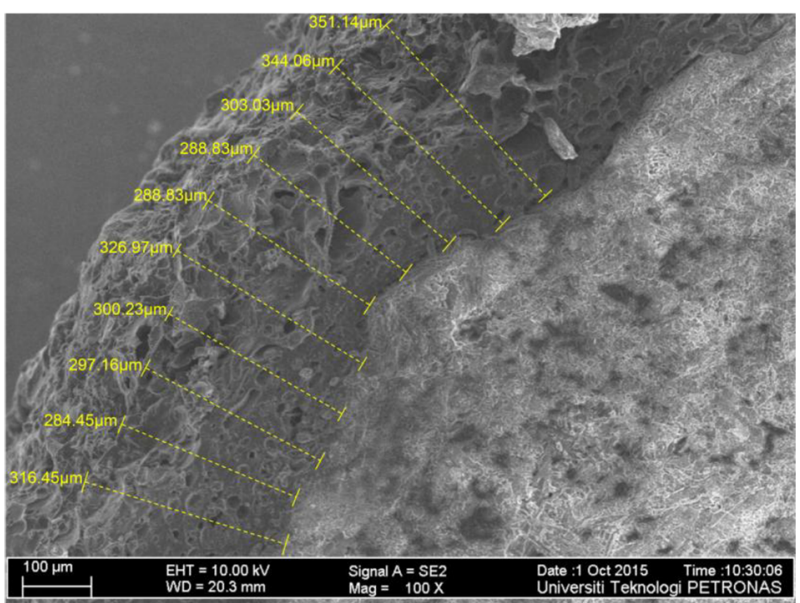

Figure 7. FESEM micrograph of a cross section of a St-PCU granule.

It can be observed that the lowest $\mathrm{CV}$ of thickness is achieved at a moderately high temperature $\left(78-80^{\circ} \mathrm{C}\right)$ and a moderate pressure of $\sim 0.2$ bar. This combination of the process variables facilitates the formation of tiny microdroplets of spray which conveniently take part in the phenomena of granules' surface wetting, spreading, and a solid film formation after solvent evaporation. Hence, the coating uniformity is better under these conditions. The interactive effect of spray temperature and atomizing air pressure on coating uniformity is shown in Fig. 8b. It can be observed that the response surface in this case is almost similar to Fig. 8a, with the only difference that the $\mathrm{CV}$ of thickness is a bit lower. The rest of the explanation is similar to the one for Fig. 8a.

In Fig. 8c, it is observed that the $\mathrm{CV}$ of coating thickness is significantly higher at the highest spray rate and lowest gas temperature. This is because of the high spray input in the system per unit time and lower dewatering capacity of the fluidizing gas. Hence, temporary aggregates are formed, which lead to rough and porous coating layers. It is quite possible that the mean coating thickness in such cases is high but the CV of coating thickness may also be high due to coating imperfections. Highest CV of thickness is observed at the highest gas temperature and lowest spray rate. It is believed that the droplet size is reduced at low spray rate (Salman et al., 2007). These microdroplets are carried away with the fluidizing gas because of the premature drying at high temperature (da Rosa and dos Santos Rocha, 2013). Some of the droplets dry on the surface of the granules before spreading and forming a regular film. Hence, a distorted coating film thus formed results in the lowest coating uniformity. On the other hand, the CV of thickness at the highest and lowest values of both the process variables is also high, 

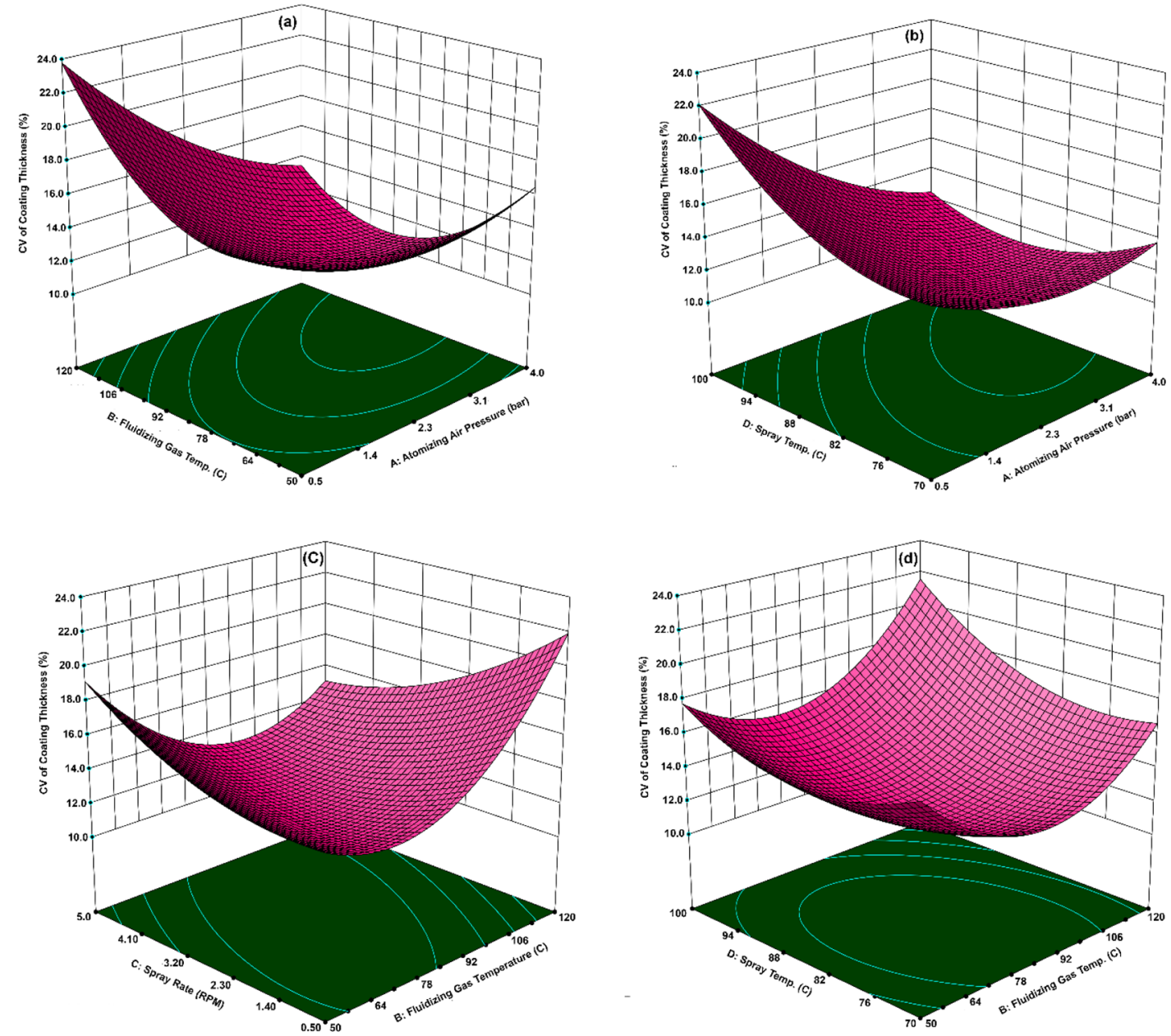

Figure 8. Response surfaces for the interactive effect of (a) fluidizing gas temperature and atomizing pressure, (b) atomizing pressure and spray temperature, (c) spray rate \& fluidizing gas temperature, and (d) spray temperature and fluidizing gas temperature, on CV of thickness.

but much lower than the ones discussed in the previous two cases. At moderately high gas temperature (78-85 ${ }^{\circ} \mathrm{C}$ ) and a spray rate of 2.30-3.20 RPM, the CV is at its lowest level, which refers to a good coating uniformity. The combined effect of spray and gas temperature in Fig. $8 \mathrm{~d}$ indicates a negative effect when both of the temperatures are at their maximum. So a very high temperature does not favor the coating uniformity of St-PCU granules. Only moderately high temperatures facilitate the formation of a good quality coating layer.

These results can be related to the literature findings undertaken by several researchers. Blouin et al. (1971) reported that urea coating quality was enhanced at a moderate atomizing pressure of 60-80 psig and a further increase to 100 psig could not make any positive difference. Donida et al. (2011) reported in their early study that urea coating uniformity was improved with an increase in the atomizing pressure because higher atomizing pressure produced smaller droplets and the spray loss was minimum. Later, the same research group undertook another study and revealed that the decreased size of the droplets with an increase in atomizing pressure causes spray loss due to elutriation and a low pressure generates bigger droplets, which are lost on the bed walls (da Rosa and dos Santos Rocha, 2010). Hence, a compromise between the two extreme conditions is necessary to have a good quality coating. Lan et al. (2011) also revealed that the coating appears porous at low atomizing pressure due to the formation of larger spray droplets. Weiss et al. (1983) reported that the coating quality decreased with increasing atomizing pressure. Tobiska et al. (2003) said that an increase in the atomizing pressure reduces the coating mass variance.

The experimental data reveals that a combination of significant coating thickness and uniformity of coating film is necessary to achieve promising results with respect to release characteristics. To further explain 
this concept, the cross sections of St-PCU granules from experimental run No. 14 and 6 are shown in Fig. 9a and $9 \mathrm{~b}$, respectively. It can be observed that the average thickness $(357.09 \mu \mathrm{m})$ of sample 14 is high but its release time $(2.611 \mathrm{~h})$ is low compared to the sample $6(5.889 \mathrm{~h})$ whose mean thickness is low $(280.47 \mu \mathrm{m})$ but with a low CV of thickness $(5 \%)$ as compared to $27 \%$ for sample 14 , which facilitates a greater retention time for the dissolved nutrient to stay inside the coating shell and exhibit better controlledrelease properties. There is yet another interesting case when not only the coating thickness is significant, but also there exists a promising coating uniformity although the release time is still low. This is because of the highly porous structure of the coating film, as can be observed in Fig. 9c which represents the film structure of a granule from sample 17. In this case, the mean coating thickness is $454.20 \mu \mathrm{m}$ and the $\mathrm{CV}$ of the coating thickness is $6 \%$ but the release time is only $1.833 \mathrm{~h}$. This is because of the high spray rate and longer process time that results in a thicker but porous coating film with relatively better coating uniformity. However, when the granule is subjected to dissolution, the large voids in the coating film easily rupture and cause a rapid release of the nutrient. Hence, it can be concluded that good controlled-release characteristics are a function of good coating uniformity, significant coating thickness and cemented compactness of the coating material on the granules' surface. This can be verified by the example of sample 26 represented in Fig. 9d for which the mean coating thickness is 339.42 $\mu \mathrm{m}$ with a $\mathrm{CV}$ of the coating thickness of $3 \%$ and the release time of $22.667 \mathrm{~h}$.

From the ANOVA analysis, a plot of actual versus predicted values of the $\mathrm{CV}$ of coating thickness is shown in Fig. 5b. It can be observed that most of the points lie near the straight line indicating better fit. The optimum values of process and response variables for the $\mathrm{CV}$ of coating thickness obtained from the statistical analysis are given in Table 4. Using these optimum values, triplicates of actual confirmation runs were performed and the results are presented in Table 4.
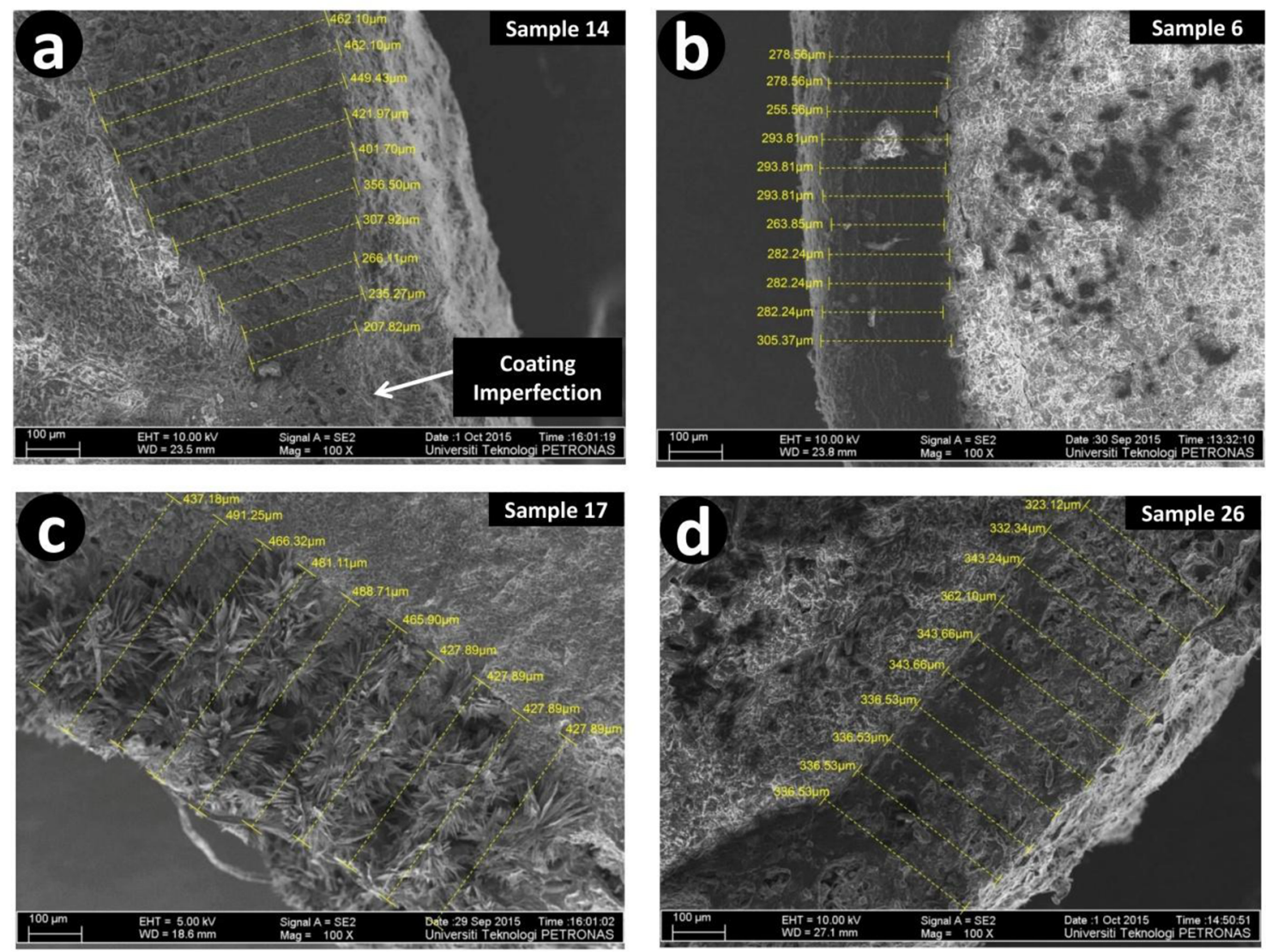

Figure 9. FESEM micrographs of (a) sample 14 with mean coating thickness of $357.09 \mu \mathrm{m}, \mathrm{CV}$ of coating thickness as $27 \%$, and release time of $2.611 \mathrm{~h}$, (b) sample 6 with mean coating thickness of $280.47 \mu \mathrm{m}, \mathrm{CV}$ of coating thickness as $5 \%$, and release time of $5.889 \mathrm{~h}$, (c) sample 17 with mean coating thickness of $454.2 \mu \mathrm{m}, \mathrm{CV}$ of coating thickness as $6 \%$, and release time of $1.833 \mathrm{~h}$, and (d) sample 26 with mean coating thickness of $339.42 \mu \mathrm{m}, \mathrm{CV}$ of coating thickness as $3 \%$, and release time of $22.667 \mathrm{~h}$. 


\section{CONCLUSION}

Urea coating has been accomplished in a rotary fluidized-bed coater using modified starch-based biopolymer as a coating material. The effect of different process conditions is studied on release characteristics and coating uniformity of controlled-release urea. The fluidizing gas temperature and coating time appear to be the most influential variables as a result of an analysis of variance (ANOVA) study. Neither very high nor very low values of fluidizing gas temperature produce promising results. The optimum values of atomizing pressure, fluidizing gas temperature, spray rate, spray temperature, and coating time resulted to be 0.23 bar, $80.38{ }^{\circ} \mathrm{C}, 2.71 \mathrm{RPM}, 85^{\circ} \mathrm{C}$, and $150 \mathrm{~min}$., respectively, for the study of nutrient release, while for the coefficient of variance of coating thickness, the optimum values of these process variables resulted to be 0.30 bar, $83.09{ }^{\circ} \mathrm{C}, 2.46 \mathrm{RPM}, 87.31{ }^{\circ} \mathrm{C}$, and 52.2 min., respectively. Increasing coating time, on the other hand, showed a positive effect only when the values of the rest of the process variables lie near the centre points. The largest release time appears to be 22.667 $\mathrm{h}$ and the lowest $\mathrm{CV}$ of coating thickness achieved is $11.59 \%$. It is concluded that better controlled-release characteristics are not only a function of good coating uniformity, but also significant coating thickness and coating film integrity. It may also be concluded that modified starch-based coating materials can be used to produce controlled-release devices in the future and the optimized parameters of this study can be used to up-scale the CRCU manufacturing process.

\section{NOMENCLATURE}

ANOVA - Analysis of variance

CCRD - Central composite rotatable design

CRCU - Controlled-release coated urea

CRFs - Controlled-release fertilizers

CV - Coefficient of variance

EDX - Energy Dispersive

X-Ray - Spectrometer

FESEM - Field Emission Scanning Electron

Microscope

$k$ - Constant

$M / M_{\infty}$ - Fraction of active nutrient

$n$ - Diffusional parameter

NUE - Nutrient use efficiency

PVOH - Polyvinyl alcohol

$\mathrm{R}^{2}$ - Coefficient of regression

RFBC - Rotary fluidized-bed coater

RMSE - Root mean square error

RSM - Response surface methodology
St-PCU - Modified-starch biopolymer coated urea St-PVOH - Polyvinyl alcohol-modified starch solution

$t$ (min.) - Nutrient release time

$\mathrm{T}_{50}, \mathrm{~T}_{75}$, and $\mathrm{T}_{100}$ (min.) - Time for $50 \%, 75 \%$, and $100 \%$ release of nutrient

\section{REFERENCES}

Abe E., Yamada N., Hirosue H. and Nakamura H., Coating mass distributions of seed particles in a tumbling fluidized bed coater, Powder Technology, 97, No. 1, p. 85-90 (1998).

Al-Zahrani S. M., Utilization of polyethylene and paraffin waxes as controlled delivery systems for different fertilizers, Industrial \& Engineering Chemistry Research, 39, No. 2, p. 367-371 (2000).

Ayub G. S. E., Rocha S. C. S. and Perrucci A. L. I., Analysis of the surface quality of sulphur-coated urea particles in a two-dimensional spouted bed, Brazilian Journal of Chemical Engineering, 18, No. 1, p. 13-22 (2001).

Blouin G. M., Rindt D. W. and Moore O. E., Sulfurcoated fertilizers for controlled release. Pilot-plant production, Journal of Agricultural and Food Chemistry, 19, No. 5, p. 801-808 (1971).

Chen L., Xie Z., Zhuang X., Chen X. and Jing X., Controlled release of urea encapsulated by starchg-poly (L-lactide), Carbohydrate Polymers, 72, No. 2, p. 342-348 (2008).

Chiellini E. and Solaro R., Biodegradable polymeric materials, Advanced Materials, 8, No. 4, p. 305313 (1996).

Cong Z., Yazhen S., Changwen D., Jianmin Z., Huoyan W. and Xiaoqin C., Evaluation of waterborne coating for controlled-release fertilizer using Wurster fluidized bed, Industrial \& Engineering Chemistry Research, 49, No. 20, p. 9644-9647 (2010).

De Oliveira W. P., Freire J. T. and Coury J. R., Analysis of particle coating by spouted bed process, International Journal of Pharmaceutics, 158, No. 1, p. 1-9 (1997).

Depypere F., Van Oostveldt P., Pieters J. G. and Dewettinck K., Quantification of microparticle coating quality by confocal laser scanning microscopy (CLSM), European Journal of Pharmaceutics and Biopharmaceutics, 73, No. 1, p. 179-186 (2009).

Dhaese A., Investigation of the Effect of Coating Time on the Inter-tablet Coating Uniformity, Using Bohle Lab Coater, Unpublished PhD thesis, Heinrich- 
Heine Universitat Dusseldorf, Dusseldorf, Germany (2014).

Donida M. W. and Rocha S. C., Coating of urea with an aqueous polymeric suspension in a twodimensional spouted bed, Drying Technology, 20, No. 3, p. 685-704 (2002).

Fernández-Pérez M., Garrido-Herrera F. J., GonzálezPradas E., Villafranca-Sánchez M. and FloresCéspedes F., Lignin and ethylcellulose as polymers in controlled release formulations of urea, Journal of Applied Polymer Science, 108, No. 6, p. 37963803(2008).

He Y., Wu Z., Tu L., Han Y., Zhang G. and Li C. Encapsulation and characterization of slowrelease microbial fertilizer from the composites of bentonite and alginate, Applied Clay Science, 109, p. 68-75 (2015).

Hemati M. R. K. V., Cherif R., Saleh K. and Pont V. Fluidized bed coating and granulation: influence of process-related variables and physicochemical properties on the growth kinetics, Powder Technology, 130, No. 1, p. 18-34 (2003).

Ito R., Golman B. and Shinohara K. Controlled release with coating layer of permeable particles, Journal of controlled release, 92, No. 3, p. 361-368 (2003).

Jin S., Wang Y., He J., Yang Y., Yu X. and Yue G. Preparation and properties of a degradable interpenetrating polymer networks based on starch with water retention, amelioration of soil, and slow release of nitrogen and phosphorus fertilizer, Journal of Applied Polymer Science, 128, No. 1, p. 407-415 (2013).

Jozwiakowski M. J., Jones D. M. and Franz R. M. Characterization of a hot-melt fluid bed coating process for fine granules, Pharmaceutical Research, 7, No. 11, p. 1119-1126 (1990).

Ko B. S., Cho Y. S. and Rhee H. K. Controlled release of urea from rosin-coated fertilizer particles, Industrial \& Engineering Chemistry Research, 35, No. 1, p. 250-257 (1996).

Lan R., Liu Y., Wang G., Wang T., Kan C. and Jin Y. Experimental modeling of polymer latex spray coating for producing controlled-release urea, Particuology, 9, No. 5, p. 510-516 (2011).

Lubkowski K., Smorowska A., Grzmil B. and Kozłowska A. Controlled-Release Fertilizer Prepared Using a Biodegradable Aliphatic Copolyester of Poly (butylene succinate) and Dimerized Fatty Acid, Journal of Agricultural and Food Chemistry, 63, No. 10, p. 2597-2605 (2015).
Lum Y. H., Shaaban A., Mohamad N., Dimin F. and Yatim N. M. Boric acid modified starch polyvinyl alcohol matrix for slow release fertilizer, e-Polymers, 16, No. 2, p. 151-158 (2016).

Luštrik M., Dreu R., Šibanc R. and Srčič S . Comparative study of the uniformity of coating thickness of pellets coated with a conventional Wurster chamber and a swirl generator-equipped Wurster chamber, Pharmaceutical Development and Technology, 17, No. 3, p. 268-276 (2012).

Mekonnen T., Mussone P., Khalil H. and Bressler D. Progress in bio-based plastics and plasticizing modifications, Journal of Materials Chemistry A, 1, No. 43, p. 13379-13398 (2013).

Melaj M. A. and Daraio M. E. Preparation and characterization of potassium nitrate controlledrelease fertilizers based on chitosan and xanthan layered tablets, Journal of Applied Polymer Science, 130, No. 4, p. 2422-2428 (2013).

Naz M. Y. and Sulaiman S. A. Testing of starch-based carbohydrate polymer coatings for enhanced urea performance, Journal of Coatings Technology and Research, 11, No. 5, p. 747-756 (2014).

Naz M. Y. and Sulaiman S. A. Slow release coating remedy for nitrogen loss from conventional urea: a review, Journal of Controlled Release, 225, p. 109120 (2016).

Naz M. Y., Sulaiman S. A., Ariwahjoedi B. and Shaari K. Z. K. Effect of pre-coat solution temperature on fluidized bed urea coatings, Surface Engineering, 31, No. 7, p. 486-491 (2015).

Ni B., Liu M., Lü S., Xie L. and Wang Y. Environmentally friendly slow-release nitrogen fertilizer, Journal of Agricultural and Food Chemistry, 59, No. 18, p. 10169-10175 (2011).

Niu Y. and $\mathrm{Li} \mathrm{H}$. Controlled release of urea encapsulated by starch-g-poly (vinyl acetate), Industrial \& Engineering Chemistry Research, 51, No. 38, p. 12173-12177 (2012).

Paulo Filho M., Rocha S. C. S. and Lisboa A. C. L. Modeling and experimental analysis of polydispersed particles coating in spouted bed, Chemical Engineering and Processing: Process Intensification, 45, No. 11, p. 965-972 (2006).

Peppas N A. Analysis of Fickian and non-Fickian drug release from polymers, Pharmaceutica Acta Helvetiae, 60, No. 4, p. 110 (1985).

Pissinati R. and Oliveira W. P. Enteric coating of soft gelatin capsules by spouted bed: effect of operating conditions on coating efficiency and on product 
quality, European Journal of Pharmaceutics and Biopharmaceutics, 55, No. 3, p. 313-321 (2003).

Riyajan S. A., Sasithornsonti Y. and Phinyocheep P. Green natural rubber-g-modified starch for controlling urea release, Carbohydrate Polymers, 89, No. 1, p. 251-258 (2012).

Rosa G. S., and Rocha, S. C. S., Effect of process conditions on particle growth for spouted bed coating of urea, Chemical Engineering and Processing: Process Intensification, 49, No. 8, p. 836-842 (2010).

Rosa G. S., and Rocha, S. C. S., Use of vinasse to produce slow-release coated urea in spouted bed, The Canadian Journal of Chemical Engineering, 91, No. 3, p. 589-597 (2013).

Rychter P., Kot M., Bajer K., Rogacz D., Šišková A. and Kapuśniak J. Utilization of starch films plasticized with urea as fertilizer for improvement of plant growth, Carbohydrate Polymers, 137, p. 127-138 (2016).

Salman A. D., Hounslow M. J. and Seville J. P. K. Granulation, in, Salman A. D., Hounslow M. J. and Seville J. P. K. (Eds.), Handbook of Powder Technol ogy, Elsevier Science, Vol. 11, (2007).

Salman O. A. Polymer coating on urea prills to reduce dissolution rate, Journal of Agricultural and Food Chemistry, 36, No. 3, p. 616-621 (1988).

Tang X. and Alavi S. Recent advances in starch, polyvinyl alcohol based polymer blends, nanocomposites and their biodegradability, Carbohydrate Polymers, 85, No. 1, p. 7-16 (2011).

Tobiska S. and Kleinebudde P. Coating uniformity: influence of atomizing air pressure, Pharmaceutical Development and Technology, 8, No. 1, p. 39-46 (2003).

Tomaszewska M. and Jarosiewicz A. Polysulfone coating with starch addition in CRF formulation, Desalination, 163, No. 1, p. 247-252 (2004).

Tsai B. S. Continuous spouted bed process for sulphurcoating urea, Unpublished $\mathrm{PhD}$ thesis, University of British Columbia, Vancouver, Canada (1986).

Weiss P. J. and Meisen A. Laboratory studies on sulphur-coating urea by the spouted bed process, The Canadian Journal of Chemical Engineering, 61, No. 3, p. 440-447 (1983).

Witono J. R., Noordergraaf I. W., Heeres H. J. and Janssen L. P. B. M. Water absorption, retention and the swelling characteristics of cassava starch grafted with polyacrylic acid, Carbohydrate Polymers, 103, p. 325-332 (2014).

Xiong H., Tang S., Tang H. and Zou P. The structure and properties of a starch-based biodegradable film, Carbohydrate Polymers, 71, No. 2, p. 263-268 (2008).

Zhao F. C., Wu A. B., Zhang L. Y., Niu C. Q., Wang X. H., Chen K. M. and Liao S. Q. Preparation of slow-released films based on the natural rubber latex modified by cassava starch, Materials Science Forum, 848, p. 152-159 (2016). 
